\title{
ENSINO E APRENDIZAGEM EM FILOSOFIA: UMA PROPOSTA EMANCIPATÓRIA
}

\author{
TEACHING AND LEARNING IN PHILOSOPHY: AN \\ EMANCIPATORY PROPOSAL
}

Luciano da Silva*

Recebido em: 05/2017 Aprovado em: 08/2017

\begin{abstract}
Resumo: O artigo busca avançar na discussão sobre o ensino e a aprendizagem em filosofia no ensino médio. Parte da relação entre didática e aprendizagem, enfatizando o ensino de filosofia como problema filosófico. Relaciona as concepções de Kant, Adorno e Freire sobre a menoridade na tentativa de contribuir para o debate sobre a educação emancipatória. A pesquisa conclui que, para contribuir com essa proposta, o currículo de filosofia precisa considerar o contexto social da escola.
\end{abstract}

Palavras-chave: Ensino de filosofia. Menoridade. Emancipação.

\begin{abstract}
The article seeks to advance the discussion about teaching and learning in philosophy in high school. Part of the relationship between didactics and learning, emphasizing the teaching of philosophy as a philosophical problem. It relates the conceptions of Kant, Adorno and Freire on the minority in the attempt to contribute to the debate on emancipatory education. The research concludes that to contribute to this proposal, the philosophy curriculum needs to consider the social context of the school.
\end{abstract}

Keywords: Teaching philosophy. Minority. Emancipation.

\section{Introdução}

As atividades de ensino de filosofia para o ensino médio são orientadas em vista do movimento dialético de reflexão sobre a prática docente em um contexto em que o protagonismo professor-aluno é fundamental para que o espaço escolar seja compreendido como possibilidade de afirmação de autonomia desses sujeitos. Partindo do pressuposto de que "ninguém escapa da educação" (BRANDÃO, 1983, p. 7), esta deve ser construída social e coletivamente, uma vez que, sem perceber, um professor pode reproduzir uma ideologia educacional que legitime a divisão de classes (ADORNO, 1995). Por isso, o debate sobre o ensino de filosofia e sua relação com o contexto social deve ser constante.

A atividade do professor se constitui por meio das relações sociais que estabeleceu ao longo da sua formação e atuação. No Brasil essa formação tem sido marcada pela introdução de tecnologias no âmbito da educação, que demandam ao professor aprender a lidar com essa nova realidade cultural. A apropriação reflexiva, por parte do docente, das "bases de informação disponíveis" (MARQUES, 2004, p. 59), constitui uma etapa necessária à compreensão da educação como "fenômeno social". Se o aluno precisa compreender a linguagem do professor, é plausível que este deve compreender

\footnotetext{
*Professor de Filosofia, UFCG, Campina Grande, PB.

Problemata: R. Intern. Fil. V. 8. n. 2 (2017), p. 104-116 ISSN 2236-8612 doi:http://dx.doi.org/10.7443/problemata.v8i2.35927
} 
e aprender a linguagem do "novo aluno", que herdou uma realidade cultural marcada pelo uso das mais variadas tecnologias. Para além do uso de tecnologias em sala de aula o atual contexto demanda às licenciaturas trabalhar não apenas com alunos egressos do ensino médio ou equivalente, mas também com aqueles que já exercem a docência, como observa Mara Marques (2004, p. 60):

\begin{abstract}
Mas como formar os docentes que já estão em exercício? Qual o papel da formação em serviço? Que ou quais contribuições a Didática oferece para estes profissionais? Que conceitos, compreensão e definições os profissionais da educação tem acerca do que seja formação? Como ensinar ao educando a se tornar cidadão, se ainda não somos cidadãos? Como preparar o educando para vida social, valorizando seu conhecimento específico, mas também valorizando sua criatividade, sua responsabilidade como pessoa e como ser social?
\end{abstract}

Essas questões reforçam a tese de Vera Candau (2011, p. 14) de que o processo de ensino e aprendizagem deve ser multidimensional, "de tal modo que articule consistentemente as dimensões humana, técnica e político-social". Desse modo, esta pesquisa propõe uma reflexão sobre o ensino de filosofia, com foco na formação do professor. Para isso, propõe relacionar os conceitos de didática e aprendizagem em filosofia a parti de Kant, Adorno e Freire como proposta emancipatória.

\title{
Didática e aprendizagem em filosofia
}

Didática "significa arte de ensinar" (COMÉNIO, 2006, p. 45) e as teorias da educação são as mais variadas. Observemos alguns exemplos: Coménio (2006, p. 45) apresentou "um método universal de ensinar tudo a todos. E de ensinar com tal certeza, que seja impossível não conseguir bons resultados". Kant (1999, p. 15) afirmou que "O homem não pode se tornar um verdadeiro homem senão pela educação. Ele é aquilo que a educação dele faz. Note-se que ele só pode receber tal educação de outros homens, os quais a receberam igualmente de outros". Adorno (1995) defende a tese de que para que Auschwitz não se repita, a educação precisa ter, em sua estrutura, uma proposta emancipatória. Freire (2016a, p. 146), ao defender uma educação baseada na relação homem-mundo, enfatizou que "Nosso papel não é falar ao povo sobre a nossa visão de mundo, ou tentar impô-la a ele, mas dialogar com ele sobre a sua e a nossa". Mészáros (2005, p. 25), por sua vez, defende a necessidade de "[...] uma radical mudança estrutural. Uma mudança que nos leve para além do capital, no sentido genuíno e educacionalmente viável do termo". 
A didática prescinde de um "conceito geral de educação" que a distancia de um conjunto de técnicas que o professor precisa dominar. Ela se desenvolve em correlação aos conceitos de educação, pedagogia e filosofia da educação (MARNOTO, 1990). Seu estudo esclarece o processo de aquisição do saber e como os métodos de ensino devem ser desenvolvidos na sala de aula. O ensino de filosofia está no campo da didática quando o professor se comporta não como aquele que sabe, porque um dia aprendeu e não mais precisa aprender, mas quando este profissional problematiza sua atividade e se compreende como parte do processo de ensino e aprendizagem.

Ensinar filosofia é um ato de comunicação que demanda intenção de quem comunica, mas também exige abertura de quem se dispõe a recepcionar o que é comunicado. Sócrates defende a tese de que a aprendizagem é um processo, não sendo possível ensinar por imposição:

- Temos então - continuei eu - de pensar o seguinte sobre esta matéria, se é verdade
o que dissemos: a educação não é o que alguns apregoam que ela é. Dizem eles que
introduzem a ciência numa alma em que ela não existe, como se introduzissem a vista
em olhos cegos (PLATÃO, 2010, VII, 518b-c).

Freire (2016b, p. 24), corroborando com o entendimento de Sócrates enfatiza que "ensinar não é transferir conhecimento, mas criar as possibilidades para a sua produção ou a sua construção". Nesse sentido, podemos compreender que para Sócrates e Freire, a escola não é o único lugar em que a aprendizagem pode acontecer. Concordamos com os dois autores nesse ponto, mas como estamos tratando do ensino e da aprendizagem nos espaços da Escola e da Universidade, nos parece plausível que o programa de ensino deve instrumentalizar o aluno sobre seu percurso no espaço de ensino. Nesse sentido, compreensão do processo de ensino é um meio fundamental para inserção do aluno no universo conceitual filosófico (MARNOTO, 1990, p. 28) e a compreensão do contexto do espaço escolar demanda tratar o ensino da filosofia como problema filosófico (CERLLETI, 2009).

O trabalho com a filosofia na sala de aula pode se desenvolver por meio de um texto que deve levar a outros textos. A didática filosófica organiza a mediação entre diferentes textos e o ensino de filosofia encontra sentido na e pela aprendizagem, que passa a tratar o aluno como interlocutor desse processo. Notadamente não há um receituário para a aula de filosofia que, por mais bem planejada que seja, não pode garantir que o resultado supere o abismo entre 0 ensino e a aprendizagem. Acreditamos que a aprendizagem em filosofia precisa lidar com o cuidado de não querer mudar atitudes por imposição, como se pretendesse mudar as histórias dos alunos e, dessa forma, correr o risco de não mais poder lidar com a espontaneidade, fundamental para o trabalho como a 
filosofia.

Notadamente, o tratamento dado aos textos filosóficos no ensino médio não pode ser o mesmo da aula da graduação. Esse nível da educação básica demanda, para além do conteúdo, uma consideração da localização e da dinâmica diária da escola. Uma escola localizada numa comunidade com baixa presença das políticas públicas do estado sente o peso dessa ausência em seu desenvolvimento. Essas circunstâncias não indicam que se pode ensinar e aprender melhor filosofia em lugar do que em outro, mas como bem destaca Cerlleti (2009, p. 8) "em função desses contextos, não será o mesmo em cada caso o que se pode - ou se deve - fazer em nome da filosofia".

A reflexão sobre o contexto da escola é fundamental também para a compreensão do desempenho do professor. Se este precisa de muitas salas de aulas, em diferentes escolas, para formar uma renda mínima que lhe permita a sobrevivência, terá um vínculo, com a filosofia, diferente daquele profissional que dispõe de tempo para se dedicar à pesquisa e preparação de suas aulas. A esse respeito, convém observar a questão que Bruce Janz (2008, p. 106) levanta: "Será que o pensamento filosófico não é afetado pelos lugares em que é praticado?" Ao nosso ver, não apenas o lugar de onde a filosofia é praticada importa, porque os contextos são diferentes, mas importa também as condições que o professor dispõe para o desenvolvimento do seu trabalho. A reflexão sobre a ontologia, metodologia, axiologia e metodologia sofre influência do lugar onde o aluno do ensino médio fala. Portanto, um professor de filosofia formado de maneira que seja capaz de pensar o conteúdo da aula a partir do contexto que a escola está inserida pode fazer uma grande diferença na formação do aluno. No entender de Cerlleti (2009, p. 8) esta é uma questão que merece nossa atenção porque o professor de filosofia do ensino médio é uma "construção subjetiva, apoiada em uma série de elementos objetivos e conjunturais". Sua atuação profissional precisa ser problematizada para uma melhor compreensão do que "que significa ensinar filosofia no ensino médio?".

Não se pode aceitar como resposta que ensinar filosofia seja a mera transmissão de conteúdos filosóficos. No caso do Brasil, como lembra Silvio Gallo, há um conteúdo formal pré-determinado que não deve ser dispensado, mas investigado com a devida atenção. Faz todo sentido que, uma vez que se tornou parte do ensino institucional, o ensino de filosofia deva ser planejado e que seja estabelecido um conteúdo mínimo para o seu desenvolvimento. Dessa forma, a questão "que é ensinar filosofia?", precisa ser tratada da mesma forma que a questão "que é filosofia?". Ambas constituem temas próprio da filosofia e não podem receber uma resposta única. Um problema recorrente a esse respeito é que a institucionalização do ensino de filosofia leva o seu desenvolvimento em sala de aula a se fixar durante muito tempo numa introdução de conteúdos 
específicos da filosofia, abreviando em muito o espaço dessas questões. $O$ domínio do conteúdo filosofia, representado comumente pelo o que, não pode ser, e não é, suficiente para a compreensão do significado da questão "Que é ensinar filosofia?".

O ensino de filosofia só recentemente alcançou seu espaço específico na educação básica brasileira. Na tentativa de fazer parte do currículo oficial do ensino médio, talvez seu maior desafio tenha se dado em 1971, com a reforma tecnicista (SAVIANI, 2013). Alguns avanços como a utilização da filosofia como conteúdo opcional no currículo desta fase da educação, só foram alcançados a partir de 1980, período em que se iniciam as discussões para a elaboração da Lei de Diretrizes e Bases da Educação Nacional (LDB), n. 9.394 de 20 de dezembro de 1996.

O resultado esperado para disciplina de filosofia só veio mesmo com a promulgação da Lei $n^{\circ} 11.684$, de 2 de junho de 2008 a qual "Altera o art. 36 da Lei no 9.394, de 20 de dezembro de 1996, que estabelece as diretrizes e bases da educação nacional, para incluir a Filosofia e a Sociologia como disciplinas obrigatórias nos currículos do ensino médio" (Caput.). A nova lei contribuiu para a abertura de novas licenciaturas em filosofia para atender a demanda do ensino médio por professores especializados. A abertura de novos espaços para atuação desta disciplina demandou mais atenção na formação de seus profissionais, tendo em vista o contexto de redemocratização do estado brasileiro. Como componente curricular da educação básica, a filosofia a filosofia pode contribuir para a interdisciplinaridade. Para isso, seu currículo precisa ser pensado a partir da orientação dos documentos oficiais, considerando as regionalidades e os diferentes contextos das instituições educacionais.

Ao nosso ver, essa relação entre os documentos oficiais e o contexto da escola pode ser pensada por meio de uma proposta de educação emancipatória. Nesse sentido, nossa intenção é compreender até que ponto o ensino de filosofia pode possibilitar ao aluno do ensino médio da escola pública o alcance de uma identidade cidadã por sua própria escolha. Trata-se de pensar uma proposta emancipatória de educação que tenha impacto na formação do professor, no âmbito da licenciatura, e se reflita na aprendizagem do aluno, no âmbito do ensino médio.

\section{Ensino de filosofia e emancipação}

A importância da filosofia para a formação humana já seria suficiente para justificar sua presença na sala de aula do ensino médio (Horn, 2009). Mas esse debate precisa ser constante, em vista de saber que papel a filosofia pode ocupar 
na formação do aluno.

A distinção que Kant estabelece entre os conhecimentos "objetivo" e "subjetivo" pode ser um bom ponto de partida para retomar esse debate. No entender do pensador alemão, o conhecimento objetivo pode ser racional, quando tem origem em princípios, e pode ser empírico quando tem origem na experiência. O conhecimento subjetivo, que se refere aos modos como o homem adquire o conhecimento, pode ser ou racional (cognitio ex principiis) ou histórico (cognitio ex datis). Mas, independentemente da origem, o conhecimento dado é histórico "naquele que o possui, quando esse não sabe nada mais do que aquilo que the é dado de fora, seja por experiência imediata, ou por narração, ou mesmo por instrução (de conhecimentos gerais)" (KANT, 1994, B 864). Nesse sentido, é possível que alguém seja capaz de explicar toda a filosofia de Kant, em quantas partes se divide e em que obra ele trata de ética ou direito, mas esse é um conhecimento histórico, por mais completo que seja, da filosofia deste pensador. O fato é que essa formação resultou de um pensamento alheio, e não da criação do próprio indivíduo: "[...] o conhecimento não resultou nele da razão e embora seja, sem dúvida, objetivamente, em um conhecimento racional, é, contudo, subjetivamente, apenas histórico. Compreendeu bem e reteve bem, isto é, aprendeu bem e é assim a máscara de um homem vivo (KANT, 1994, B 864).

Por sua vez, o conhecimento subjetivo é racional quando tem origem na própria razão do homem, "donde pode também resultar a crítica e mesmo a rejeição do que se aprendeu, isto é, quando forem extraídos de princípios" (KANT, 1994, B 865). Em consequência disso, Kant vai afirmar que: "Entre todas as ciências racionais (a priori) só é possível, por conseguinte, aprender a matemática, mas nunca a filosofia (a não ser historicamente): quanto ao que respeita à razão, apenas se pode, no máximo, aprender a filosofar" (KANT, 1994, B 865). (grifos do tradutor).

Podemos ver que a filosofia, para Kant, não é algo concreto que pode ser identificado no cotidiano, mas "uma simples ideia de uma ciência possível [...] que procuramos aproximar-nos por diferentes caminhos [...]" (KANT, 1994, B 866). É, portanto, da divisão do conhecimento subjetivo em racional e histórico, que decorre a seguinte tese:

Até então não se pode aprender nenhuma filosofia; pois onde está ela? Quem a possui? Por que caracteres se pode conhecer? Pode-se apenas aprender a filosofar, isto é, a exercer o talento da razão na aplicação dos seus princípios gerais em certas tentativas que se apresentam, mas sempre com a reserva do direito que a razão tem de procurar esses próprios princípios nas suas fontes e confirmá-los ou rejeitá-los (KANT, 1994, B 866).

O contexto em que essa tese é apresentada na Primeira Crítica possibilita 
a superação do mal-entendido em torno de sua intepretação e nos permite perceber a contribuição do pensamento de Kant para um ensino de filosofia emancipatório no ensino médio. Lídia Rodrigo (2004, p. 91) comenta, a esse respeito, que a interpretação que diz que "[...] não é possível aprender filosofia, mas apenas filosofar [...]" pode comprometer o estudo da história da filosofia, substituindo-o por dinâmicas que prometem ao aluno pensar por si mesmo, mas que acabam por distanciar o trabalho direto com a filosofia. Essa passagem do texto de Kant reflete um embate que pode ser percebido nas aulas da licenciatura em filosofia quando se reflete sobre como deve ser conduzida a aula de filosofia no ensino médio, a saber: como o trabalho com a filosofia pode contribuir para a compreensão e superação de uma possível menoridade entre os alunos do ensino médio?

Ao nosso ver, Kant aponta um caminho para essa questão no opúsculo Resposta à pergunta: o que é iluminismo? (1992), no qual chama a atenção para o fato de que estar na menoridade ou tentar dela sair é uma escolha de cada sujeito. De acordo com essa tese, ninguém pode promover a emancipação de outro, porque para muitas pessoas a menoridade pode representar uma zona de segurança, já que a maioridade implica em assumir responsabilidades pelos próprios atos. Nesse sentido, a presença da filosofia na sala de aula do ensino médio não é garantia de contribuição para a emancipação do aluno. Mas sua presença nesse nível do currículo da educação básica é fundamental, porque o diferencial pode vir em consequência dos conteúdos tratados a partir de um ponto de vista filosófico.

A concepção de Kant sobre a menoridade mostra que a emancipação deve se realizar primeiramente em cada sujeito e, em um sentido gradativo, alcançar uma escala global. Mas, a saída da menoridade para um indivíduo é um processo lento e constante e este esforço pode se tornar mais difícil quando se tenta enxerga-lo em um âmbito maior, como no caso de uma cidade ou estado, conforme ressalva do próprio Kant (1992, p. 13) ao comentar que:

[...] um público só muito lentamente pode chegar à ilustração. Por meio de uma revolução poderá talvez levar-se a cabo a queda do despotismo pessoal e da opressão gananciosa ou dominadora, mas nunca uma verdadeira reforma do modo de pensar. Novos preconceitos, justamente como os antigos, servirão de rédeas à grande massa destituída de pensamento.

Notadamente, o espaço público no qual deve ocorrer essa formação vai além do espaço escolar que é bem mais complexo que aquele que Kant compreendia em seu tempo. Contudo, no contexto em que escreveu Educação e Emancipação, Adorno considera atual a tese kantiana. O pensador da Escola de Frankfurt demonstra preocupação com o fato de que a literatura sobre a educação, em sua estrutura, não apresenta inclinação para a emancipação, mas 
"um conceito guarnecido nos termos de uma ontologia existencial de autoridade, de compromisso, ou outras abominações que sabotam o conceito de emancipação" (ADORNO, 1995, p. 172). A autoridade se apresenta em inúmeras faces na realidade social e Adorno considera que uma de suas formas, a autoridade técnica, pode ser percebida na figura do professor que supostamente tudo sabe e que, por essa aparência, impõe ao interlocutor uma menoridade. Nesse sentido, ao apropriar-se da tese de Kant sobre a emancipação, Adorno parece compreender que a maioridade não pode ser alcançada pelo simples fato de se contestar uma autoridade estabelecida. No seu entender, se faz necessário um encontro entre aquele que se encontra em situação de menoridade e aquele que representa a figura da autoridade. No espaço educacional isto significa que não faz sentido pensar uma escola sem professores, embora estes representem, por vezes, os opressores. Isto posto, Adorno também nos lembra que a menoridade pode estar implícita na figura da autoridade e que, não raro, esta é, tão somente, um ideal de quem a representa. Portanto, a menoridade não é necessariamente uma escolha do indivíduo, porque a "[...] emancipação precisa ser acompanhada de uma certa firmeza do eu [...]" (ADORNO, 1995, p. 180).

No entender de Adorno, sem a garantia de condições socioeconômicas e psicológicas, a maioridade se mostra uma meta inalcançável. Por isso, a emancipação deve ser compreendida como um "vir-a-ser", visto que nenhuma pessoa pode alcança-la apenas por sua decisão numa sociedade em que recebe influência dos mais diferente setores: "O problema propriamente dito da emancipação hoje é se e como a gente - e quem é 'a gente', eis uma grande questão a mais - pode enfrentá-lo" (ADORNO, 1995, p. 182). A concepção de emancipação que Adorno apresenta, nos leva a compreender o quanto se faz necessário uma reforma estrutural da educação que possibilite ao aluno tornarse protagonista de sua vida: "[...] a única concretização efetiva da emancipação consiste em que aquelas poucas pessoas interessadas nesta direção orientem toda a sua energia para que a educação seja uma educação para a contradição e para a resistência" (ADORNO, 1995, p. 183).

As concepções de Kant e Adorno podem fundamentar a presença desta disciplina no currículo da educação básica como um sinal promissor de preparação de um espaço favorável à emancipação das gerações futuras. Nesse sentido, não há nenhum problema em que a filosofia seja ensinada com vistas a formação do cidadão, desde que seu caráter essencial, de problematização do que está posto seja preservado. Mas, para pensar a proposta de uma educação emancipatória mais próxima da realidade das escolas brasileiras mais afastadas dos grandes centros, nos parece fundamental considerar que Paulo Freire, na justificativa da Pedagogia do oprimido, ao discorrer sobre a descoberta que o 
homem oprimido faz de si mesmo, entende a menoridade como uma dialética da realidade histórica, enraizada a tal ponto que o homem não reconhece sua humanidade:

\footnotetext{
Vocação negada, mas também afirmada na própria negação. Vocação negada na injustiça, na exploração, na opressão, na violência dos opressores. Mas afirmada no anseio de liberdade, de justiça, de luta dos oprimidos, pela recuperação de sua humanidade (FREIRE, 2016, p. 62).
}

Na concepção de Paulo Freire, a menoridade se verifica no oprimido e no seu opressor e, em ambos, impede o alcance do ser mais, da afirmação de si mesmo. Não significa que o homem está determinado historicamente à menoridade que lhe foi imposta. A condição em que se encontra é "[...] resultado de uma 'ordem' injusta que gera a violência dos opressores e esta, o ser menos" (FREIRE, 2016, p. 63).

No pensamento de Freire sobre a emancipação confluem, a nosso ver, o idealismo de Kant e realismo de Adorno: "E aí está a grande tarefa humanista e histórica dos oprimidos - libertar-se a si e aos opressores" (FREIRE, 2016, p. 63). A proposta de reforma da educação que o pensamento de Freire propõe não se restringe a apenas um setor da sociedade, mas se estende a toda a sociedade.

Da concepção de emancipação que perpassa os pensamentos de Kant, Adorno e Freire, é possível pensar a filosofia como uma atividade, um processo, e não apenas como um produto de sistemas e conceitos produzidos pelos filósofos ao longo da história e que agora deve ser transmitido aos alunos como uma doutrina. Deve-se, diante desse contexto, partir do pressuposto de que a filosofia é essencial à educação como um todo. Silvio Gallo defende que é possível eleger o ensino da filosofia só do ponto de vista histórico, ou só do ponto de vista do filosofar, mas que não é possível filosofar sem partir da história da filosofia. O que se faz urgente, segundo o autor, é superar a dicotomia "aprender filosofia (produto) ou aprender a filosofar (processo)" (GALLO, 2012, p. 44).

Desse ponto de vista, um professor de filosofia deve deixar claro para os alunos que não existe uma única filosofia, mas várias, e que a importância desta disciplina está no fato de que ela trata de questões de longo alcance, importantes para a humanidade; que os filósofos se arriscaram ao proporem teses em oposição aos consensos estabelecidos em suas épocas e que o exercício da filosofia consiste, sobretudo, em aprender a perguntar bem, o que pode proporcionar ao aluno o senso crítico para desconfiar do que lhe é dado como produto pronto e acabado. O professor precisa compreender que o que ele ensina não será necessariamente aprendido pelo sujeito em formação, porque não é possível exercer controle sobre o aprendizado do aluno (GALLO, 2012). 
É fato que o que é ensinado não será necessariamente aprendido. Podese até exercer um controle sobre o ensino, mas não se pode fazer o mesmo quanto ao ato de aprender. O aprendizado é algo sobre o qual podemos ter controle, talvez, sobre o ponto de partida, mas não sobre o ponto de chegada. Portanto, uma aula pode ser muito bem conduzida pelo professor, mas não há garantias de que sensibilizará o aluno. No mesmo sentido, uma boa reação do aluno ao conteúdo da aula não pode ser compreendida como o alcance da sua maioridade. A aula de filosofia é apenas uma semente que o professor lança ao solo, a cabeça do aluno, mas da qual não pode ter certeza se germinará: "[...] pode haver métodos para ensinar [...], mas não há métodos para aprender" (GALLO, 2012, p. 47). O aprendizado em filosofia demanda aprender esperar. Dessa forma, o ensino da filosofia é possível, porque a filosofia é sempre uma busca, sempre um aprendizado que se dá através do exercício do filosofar. Todo esse processo revela o vir-a-ser da educação emancipatória, de que falam Kant, Adorno e Freire.

Nesse contexto, a aula de filosofia não deve ser organizada no sentido da produção de um consenso, mas de orientar a produção de pontos de vistas distintos e o professor não deve ser um explicador de textos, porque isso configura sujeitar o aluno a sua perspectiva. Cabe-Ihe orientar o educando na construção de sua emancipação.

\section{Conclusão}

Explicar a filosofia é fazer o contrário do que este saber orienta, por isso essa atividade precisa ser problematizada constantemente (RANCIÈRE, 2015), como uma atividade que supere qualquer possibilidade de reprodução do pensamento alheio (DELEUZE; GUATARRI, 1992). Esta é uma atividade que deve ser desenvolvida com especial atenção no ensino médio. Na mesma perspectiva de Deleuze e Guatarri, Sílvio Gallo propõe que essa atividade do pensamento se dê por meio de uma "educação menor", que tem a ver com a prática que deve ser escolhida pelo professor em sala de aula a partir do contexto que esta apresenta. Este é um aspecto importante para o desenvolvimento de uma educação emancipatória. Ao nosso ver, o lugar de onde a filosofia é praticada importa, porque os contextos são diferentes.

A filosofia tem uma função social que é explicar a condição do homem no mundo. Por isso, se faz necessário compreender a relação histórica da construção do conhecimento filosófico com o ensino de filosofia no ensino médio. Cabe, nesse sentido, compreender a complexidade social da realidade brasileira por meio de uma reflexão sobre a especificidade do ensino de filosofia. Ao nosso 
ver, isto implica pensar a partir das teses de Kant, Adorno e Freire, qual deve ser a função da filosofia na sala de aula do ensino médio. Notadamente, esta não é uma tarefa fácil, porque se trata de um problema que pode ser observado desde o âmbito da graduação, em que o aprendizado em filosofia exige um rigor próprio da reflexão filosófica, condição sem a qual não é possível formar um bom professor, embora não seja a única.

É nesse sentido que esta disciplina precisa assumir o caráter de uma formação humana emancipatória, porque quando se trata de filosofia para préadolescentes e adolescentes a escola é o espaço, por excelência, mais adequado. É na escola que o aluno do ensino médio pode encontrar as condições necessárias para realizar a experiência filosófica adequada à sua idade e, dessa forma, posicionar-se, assumir-se e reconhecer-se como si mesmo no contexto no qual está inserido. Mas esse ensino emancipatório só é possível quando o professor recebe uma formação didática consistente para compreender esse desafio.

\section{Referências}

ADORNO, Theodor. Educação e emancipação. Rio de Janeiro: Paz e Terra, 2011.

BRANDÃO, Carlos Rodrigues. O que é educação? São Paulo: Brasiliense, 1983.

BRASIL. Presidência da República. Casa Civil. Subchefia para Assuntos Jurídicos. Lei $n^{\circ} 11.684$, de 2 de junho de 2008. Disponível em: http://portal.mec.gov.br/setec/arquivos/pdf/rceb04_06.pdf. Acesso em: 7 de julho de 2013.

BRASIL. Lei de Diretrizes e Bases da Educação: Lei no 9.394/96 - 24 de dez. 1996. Estabelece as diretrizes e bases da educação nacional. Brasília, 1998.

CANDAU, Vera Maria (Org.). A didática em questão. 32ª ed. Petrópolis, RJ: Vozes, 2011.

CERLETTI, Alejandro. O ensino de filosofia como problema filosófico. Autêntica, 2009.

COMÉNIO, João Amós. Didática Magna: Tratado da arte universal de ensinar tudo a todos. 5ํㅡ. ed. Trad. Joaquim Ferreira Gomes. Lisboa: Fundação Calouste 
Gulbenkian, 2006.

DELEUZE, G.; GUATARRI, F. O que é Filosofia? Trad. Bento Prado Junior e Alberto A. Munoz. São Paulo: Editora 34, 1992.

FREIRE, Paulo. Pedagogia do oprimido. $60^{\underline{a}}$ ed. Rio de Janeiro: Paz e Terra, 2016a.

. Pedagogia da autonomia: Saberes necessários à prática educativa. $53^{\underline{a}}$ ed. Rio de Janeiro: Paz e Terra, 2016b.

GALLO, Silvio. Metodologia do ensino de filosofia: uma didática para o ensino médio. São Paulo: Papirus, 2012.

JANZ, Bruce. A filosofia como se o lugar importasse: a situação da filosofia africana. - In. CAREL, Havi; GAMEZ, David (Orgs.). Filosofia contemporânea em ação. Trad. Fernando José R. da Rocha. Porto Alegre: Artmed, 2008.

KANT, I. Resposta à pergunta: que é esclarecimento? - In. KANT, I. A Paz Perpétua e outros opúsculos. Trad. Artur Morão. Lisboa: Ed. 70, 1992.

- Crítica da Razão Pura. Trad. Manuela Pinto dos Santos e Alexandre Fradique Morujão. Lisboa: Calouste Gulbenkian, 1994.

Sobre a pedagogia. $2^{\mathrm{a}}$ ed. Trad. Francisco Cock Fontanenella.

Piracicaba: Editora Unimep, 1999.

MARNOTO, Isabel (Coord.). Didática da Filosofia. Vol. 1. Lisboa: Universidade Aberta, 1990.

MARQUES, Mara Simões C. A didática e a necessidade da formação docente. In. RODRIGUES, Janine Marta C.; RÊGO, Rogéria Gaudêncio do (Orgs).

Formação docente: coletando textos, discutindo ideias. João Pessoa: Editora Universitária, UFPB, 2004.

MÉSZÁROS, I. A educação para além do capital. Trad. São Paulo: Boitempo, 2005.

PLATÃO. A República. $12^{\underline{a}}$ ed. Trad. Maria Helena da Rocha Pereira. Lisboa: Fundação Calouste Gulbenkian, 2010. 
RANCIÈRE, J. O mestre ignorante: cinco lições sobre a emancipação intelectual. 3. Ed. Trad. Lílian do Valle. Belo Horizonte: Autêntica, 2015;

RODRIGO, Lídia Maria. Aprender filosofia ou aprender a filosofar: a propósito da tese kantiana. - In. GALLO, Silvio; DANELON, Márcio; CORNELLI, Gabriele (Orgs.). Ensino de filosofia: teoria e prática. ljuí: Ed. Unijui, 2004.

SAVIANI, Demerval. História das ideias pedagógicas no Brasil: 4. Ed. Campinas, SP: Autores Associados, 2013. 